\title{
The IT Performance Evaluation in the Construction Industry
}

\author{
Heng $\mathrm{Li}^{1}$, Zahir Irani ${ }^{2}$ and Peter E.D. Love ${ }^{3}$ \\ ${ }^{1}$ Department of Building and Real Estate, Hong Kong Polytechnic University Hung Hom, \\ Kowloon, Hong Kong \\ ${ }^{2}$ Department of Information Systems and Computing, Brunel University, Uxbridge \\ Middlesex, UB8 3PH, UK
}

\author{
${ }^{3}$ School of Architecture and Building, Deakin University, Geelong, Victoria, 3217, Australia
}

\begin{abstract}
To date there has been limited published work in the construction management and engineering literature that has provided empirical evidence to demonstrate that IT can improve organizational performance. Without an explicit understanding about how IT can be effectively used to improve organizational performance, its justification will remain to be weak for managers. To ensure the continuous increase in IT based applications in the construction industry, sufficient evidence has to be provided for management in various professions of the construction industry to evaluate, allocate and utilize appropriate IT systems. In an attempt to explore the relationship between IT and productivity, an empirical investigation of 60 Professional Consulting Firms (PCF) from the Hong Kong construction industry was undertaken. A model for determining the organizational productivity of IT is proposed, and the methodology used to test the model is described. The findings are analyzed and a cross-profession comparison of the results indicated the differences in the use of IT. The research findings are discussed with similarities being drawn. The limitations of the research are then presented and discussed. The implications of the findings and conclusions then fully presented.
\end{abstract}

Keywords: IT, decision-making, complexity, integration, productivity, survey.

\section{INTRODUCTION}

The construction industry has several unique features which distinguish it from other industries; namely the construction industry is features include the fragmental nature, one-off projects, and multiparticipants

Developments in information technology (IT) have the potential to affect business strategies, organizational structures, and management processes. From being essentially a component of an organization's internal control system (administration) in the 1980's, the IT revolution over the last decade has made IT an integral part of many core business activities. Information technology now contributes to all management functions of planning, organizing, and business operations. Integrating, however, IT within a organization's business needs so that it creates value for the company, project and their clients, remains a key management task. As the use of IT in construction is beginning to expand, organizations are starting to realize that IT can be used to gain and sustain a competitive advantage. Accordingly new technological advancements are placing increasing demands on design and construction organizations (Ahmad et al., 1995). Despite these increasing demands, however, the ways that work is performed is inert to such technological advancements. The implementation of IT into an organization and its measurement of effectiveness are a problematic task but it is especially perplexing for the construction industry because of its heterogeneous nature and unusual characteristics (Choi and Ibbs, 1990; Sanvido and Mederos, 1990).

Love and Gunasekaran (1997) suggest that the benefits of IT are not being attained for two reasons: Firstly, organizations in construction have been reactive to change, simply superimposing IT into hierarchical structures that are composed of ineffective and inefficient processes, which have not been designed for its support. Essentially, IT has been merely used to automate existing processes, thus exacerbating the already existing communication problems that exist. Secondly, IT has been implemented in an adhoc manner as organizations eschew devising strategic and tactical implementation strategies for its implementation (Betts, 1995).

To date there has been limited published work in the construction management and engineering literature, with empirical evidence that demonstrates that IT can improve organizational performance (Li, 1996a). Without an explicit understanding about how IT can be effectively used to improve productivity and organizational performance, its justification will remain weak for 
managers. To ensure the continuous increase in IT based applications in the construction industry, sufficient evidence has to be provided for management in various professions of the construction industry to evaluate, allocate and utilize appropriate IT systems.

This paper presents an empirical investigation of the relationship between IT and the productivity of 60 Professional Consulting Firms (PCF) from the Hong Kong construction industry. The first section of the paper provides an overview to managing IT in construction. A model for determining the organizational productivity of IT is then proposed, and the methodology used to test the model is described. The findings are analyzed and a cross-profession comparison of the results indicates the differences in use of IT. The research findings are then discussed with similarities being drawn. The limitations of the research are presented and discussed. Finally, the implications of the findings and conclusions are drawn from the findings.

\section{THE NATURE OF THE CONSTRUCTION INDUSTRY}

The construction industry is heterogeneous in the nature of its organizations. In order to procure a construction project, a variety of organizations are temporarily combined to create a 'temporary multiorganization' (TMO) (Cherns \& Bryant 1984) to discuss and exchange information. When construction problems arise, relevant organizations have to work together to determine appropriate concessions and compromises before solutions can be obtained (Alty 1993). The construction industry is centered around projects in which organizations come to work together within the durations of the projects. Each project is unique in the sense that there are 'properties' of construction problems that are inseparable from the project. In solving construction problems, a great deal of solvers' efforts are placed on the understanding of the problems in order to recognize the similarities of the problems at hand with previous solved problems. The similarities will enable solvers to recall their experiential knowledge, as there is no sufficient formal and procedural knowledge to solve construction problems, construction problem solvers have to reply on their experiential knowledge.

\section{MANAGING IT IN THE CONSTRUCTION INDUSTRY}

A major issue facing managers when IT is introduced into an organization is the effect that they have on the complexity of the management task. The management of IT in organizations is considered to be a difficult task because it affects strategy, culture, structure, and processes. In the context of the project, for example, communication and coordination problems frequently arise between participants. In many instances poor interorganizational relations develop over conflicting goals, and priorities. An explanation for this might be a difference in the nature of projects inasmuch as participants often "speak a different language" and operate in different professional and organizational cultures and sub-cultures (Love et al., 1999; Irani and Sharp, 1997; Irani et al., 1997). Furthermore participants may operate under different performance criteria, which may also induce conflict.

Technological diversity between organizations in the construction process can add to the complexity of the project management task. The proliferation of operating systems, software, and standards contribute to the complexity of decision making. The needs and requirements for IT should be evaluated at both organizational and project level. If IT is not managed in line with an organization's needs, information processes will become ineffective and consequently may impair decision-making. The management of construction like most other industry's requires accurate information; therefore it is considered essential that IT is effectively utilized. Information technology may be considered a relatively new technological innovation, as a result, managers lack of experience and understanding of it makes their task difficult, and decision making more problematic (Li, 1996b).

Many practitioners have commented on the difficulty of keeping up to date with the advancement and innovations in both technological and software developments. Expressing such concern that the economic climate has not enabled them to devote the necessary time and money to follow advancements in IT (Love et al., 1996). In the case of contractors, they are traditionally accustomed to intense price competition, and therefore tend to focus on the bottom line financial impact (Hochstrasser, 1992), thus facing difficulties in justifying investments in advanced technology (Hampson and Tatum, 1994). Despite the complexity associated with managing IT, Keen (1991) suggests that IT can reduce complexity in organizations. He suggests that IT can simplify work procedures and coordination. For example, the use of electronic data interchange (EDI) can be used to eliminate the cumbersome paperwork associated with purchasing and invoicing of materials and supplies, such as concrete, hardware, and plant. Keen (1991) further suggests that IT can improve communication by using electronic links such as e-mail, video conferencing and networks for sharing information. It is now become a tactical necessity, especially with the increasing popularity of partnering and strategic alliances that organizations electronically integrate their IS with 
each other. By doing so the flow of information between organizations may improve, thereby enhancing the effectiveness of decision-making. Indeed, competitive and economic advantages may also be acquired. When IT is effectively integrated into an organization the following may occur:

- $\quad$ teamwork and coordination may be enhanced. For example, it may make it easier for an estimating department to work closer with site management through a communication network so that their subcontract estimates can be monitored and compared with actual trade letting figures;

- transactions between organizations can be made quicker and more efficient. For example, EDI or electronic just-in-time systems (JIT) can be used to purchase and supply, and give instant access to the availability and price of goods. Ordering and invoicing can occur (e.g., concrete, plant, and day labor) 'on-line' rather 'than on- paper' which is concomitant with delays; and

- alliances with subcontractors and suppliers may be ameliorated through electronic links. For example linked computer-aided-design (CAD), computer-integrated-construction (CIC) and computer-aided-manufacture (CAM) systems permit the rapid prototyping and production of components by subcontractors and suppliers (e.g., steel fabrication).

As IT applications become ubiquitous to construction, managing IT becomes inexorably complex. Consequently, there is a need for integrating intra-and-inter-organizational business units and operations, so that the benefits of IT can be harnessed both internally and externally. However, it is also important that organizations do not loose sight of the cost implications associated with the adoption of new technology (Hochstrasser, 1992; Irani et al., 1997; Irani et al., 1998).

\section{Investment and Performance}

The recession of the early 1990's forced many organizations to re-formulate their IT/IS budgets, which resulted in many companies significantly reducing their investments in new systems and technology. However, investment confidence in IT appears to be rising again, with Heath and Swinden (1992) predicting that by the millennium, the whole IT industry will account for $10 \%$ of world economic activity. This rise in organizational IT expenditure is considered by Alter (1999) to be attributed to many industry's turning to IT, to help them deal with their ever more intensive competitive pressures. The significance of IT can be indicated by the high levels of capital investment directed to computer systems, and communication networks. Although, simply spending more money on IT does not guarantee performance improvements (Strassman, 1990). Yet for many organizations IT has not yielded significant gains in productivity and economic returns as initially $(\mathrm{Li}$, 1996a; Love, 1996). In construction, the most prevalent use of IT is that of computers for word processing and spreadsheets for office and contract administration (Best et al., 1996; Dawson, 1994).

A study of the role of IT in the office work, with a specific focus on word processing found that most implementations of the technology involved the automation of routine tasks; only a small proportion of offices attempted to be innovative (Taylor, 1987). Furthermore, the increasing use of spreadsheets has led to a generation of more numbers and more "sensitivity" analyses, although their effect on productivity has been incremental (Scott-Morton, 1991). Therefore the problem may not necessarily be with the application of IT but the processes that are used in its support. Organizations commonly tailor IT to suit their existing processes, as most processes have evolved without ever being designed. Explicitly, information is a key element that drives processes. It harnesses together both activities in a process and its participants. As the construction process overflows with copious amounts of information, the effective control and management of information is a demanding task. Construction organizations typically apply IT to cope with these increasing demands. Research conducted by Björk, (1993) and Abudayyeh and Rasdorf (1992), suggest that IT can boost productivity in construction. For instance, CAD, construction automation, and decision support systems can abet an organization's responsiveness to design changes, reduce construction costs, and also improve the effectiveness of their decision-making.

In construction, the typical process of initiating an IT application starts when an individual or group thinks it has a task or operation that could be improved by its implementation (English, 1993). This process continues as informal discussions over a period of time until management makes a decision to implement the IT system. Research undertaken by English (1993) reveals that most organizations have no scheme to measure the performance of their IT investment. Due to the lack of evaluation protocols that exist for evaluating the performance of IT, the initial reasons for investing and introducing IT become unclear and poorly focused. Consequently, IT applications appear may fail to deliver tangible benefits to organizations.

While there is ample research on IT in the construction management and engineering literature and its potential benefits (e.g., Björk, 1993; Abudayyeh and Rasdorf, 1992; Brandon, 1983), 
there has been no serious attempt at evaluating its performance. Successful stories of IT applications in the construction industry seldom report on it's effective practical application, and often represent only the perspective of IT developers, not that of managers and those individuals that actually use the application to perform their daily tasks.

The evaluation of IT performance in the construction management literature has not been addressed. Without a measure, it is difficult to maintain the support of management for introducing IT and their support for introducing new hardware and software applications (Tucker et al., 1996).

\section{MEASUREMENT MODEL: RATIONALE FOR TESTING}

The business literature abounds with evaluation models for investing in IT. This is entirely reasonable, as the organizational approach starts from the premise that the effectiveness of investment in IT will be influenced by the process in which the investment was implemented (Amoroso et al., 1992; Conrath and Sharma 1992; Davis 1989; Bowen 1986; Young 1984). However, this approach could be criticized for not yet shedding much light on the development of a performance evaluation model that might guide corporate decision-makers. In order to establish a better understanding of the contribution of investments in IT to organizational performance in PCF's, this research utilizes a model that measures the relationship between the IT Investment Index (ITII) and the Annual Net Profit Per Employee $(A N P E M)$, as indicated in Figure 1. The value of ITII is a linear aggregation of values of three constructs:

1. Number of PCs as the percentage of total employees

2. Value of IT as a percentage of total value of assets

3. Budget for IT as a percentage of total budget

The three constructs measure the level of investment in IT that has already committed and implemented by the organization. It is assumed, in line with Brynjolfsson (1993), that there is a lag of approximately one year before any effect of investments in IT can be manifested in organizational performance. In other words, in measuring the effect of IT on organizational performance, it is more important to focus on investments that have been committed and implemented, rather than on future investments of IT. This clearly has implications for strategic planning, as empirical evidence would appear to suggest managers focus on retrospective investments as opposed to future strategic deployments (Young 1984).
The variable ANPEM directly measures the profitability of the firm. It is important to note that there are many indicators that can be used to measure organizational performance. For example, Delone and McLean (1992) summarized three indicators that are commonly used in measuring the impact of IT to business firms: system quality, information quality, and employee empowerment. However, from discussions with PCF's, the authors realized that these indicators are extremely difficult to measure. These indicators are therefore not included in the model, so as to avoid introducing any unnecessary ambiguities and vagueness into the results.

Discussions with PCF's revealed that they could only identify a few examples where investments in IT/IS were justified by increases in non-productive measures, such as labor loyalty and employee satisfaction. However, the PCF's stressed that in most investment decisions, management would expect an increase in profitability after investing in IT/IS. Based on this finding the authors have assumed the use of ANPEM as the prime indicator for measuring organizational performance.

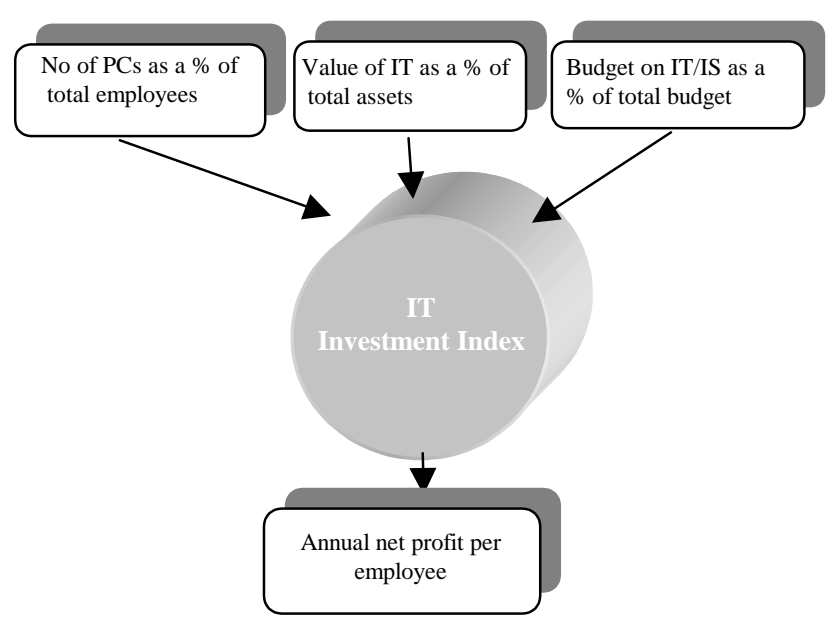

Figure 1. Framework of the measurement model

\section{METHODOLOGY}

The research started with a literature review that identified a research need. As a result, the authors developed a hypothesis that sought to test the following:

\section{There is a relationship between the use of IT and professional consulting firms' productivity.}

Clearly, in support of the hypothesis lie ITII and $A N P E M$, which will act as the vehicle to empirically, validate the proposed theoretical conjecture. 
A telephone survey was conducted with 20 engineering firms, 20 architectural firms, and 20 quantity surveying firms. Among the 20 engineering firms, 12 were building services design firms, and 8 were structural design firms. The firms were randomly selected from the Hong Kong telephone directory. As a result of the size of the construction industry, it was assumed that 20 randomly selected companies would reflect representative applications and their impact to the industry. During the telephone conversation, the researchers firstly explained the purpose of this research project, then the following four principal questions were presented to the general managers of the firms:

- What is the percentage of PC numbers over the number of total employees?

- What is the percentage of the value of IT in the total assets of your company?

- What is the percentage of budget for IT in the total budget of this financial year?

- What is the annual net profit per employee?

These questions provided information for the three constructs, which were used to derive the value of ITII, and the value of ANPEM. One notable advantage of this survey was its efficiency: for a telephone conversation with each firm, it only took about 5 to 20 minutes for the senior manager to provide answers to the questions. Responses to the questions from the managers surveyed were positive, as it did not consume as much of their time as many other surveys would require from them (Bradburn and Sudman, 1979). The results from the survey are listed in Appendices 2, 3 and 4. In order to maintain commercial confidentiality, identities of the surveyed firms were omitted in this paper.

\section{ANALYSIS OF RESULTS}

Figures 2, 3 and 4 display the distribution and correlation between ANPEM and ITII. The value of ITII is derived as the average of the values of question 1, 2 and 3. Comparisons of the results reveal that the correlation between the use of IT and annual net profit per employee in QS firms with a correlation coefficient of 0.53 . This indicates that IT in QS firms may have a positive impact on the annual productivity. Similarly, this is also the case for architectural firms who were found to have a correlation coefficient of 0.21 , which suggests that the use of IT may have a positive, yet a reduced, impact on the annual productivity.

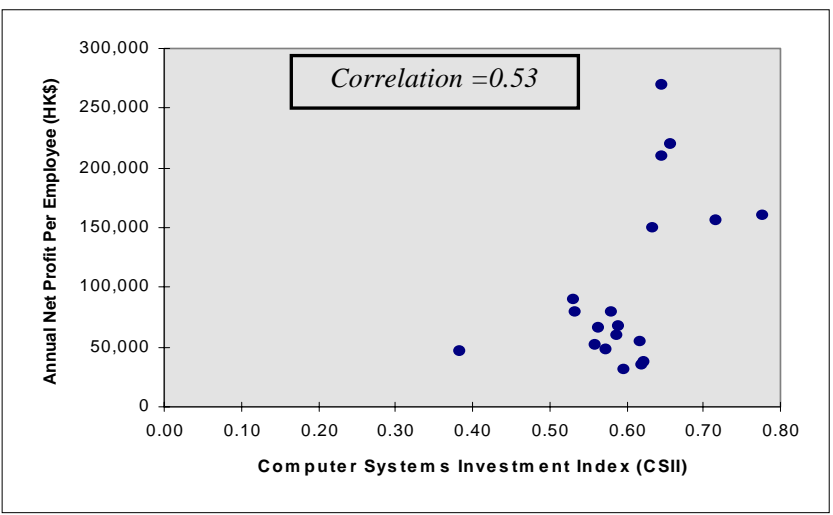

Figure 2. ITII vs. ANPEM for QS firms

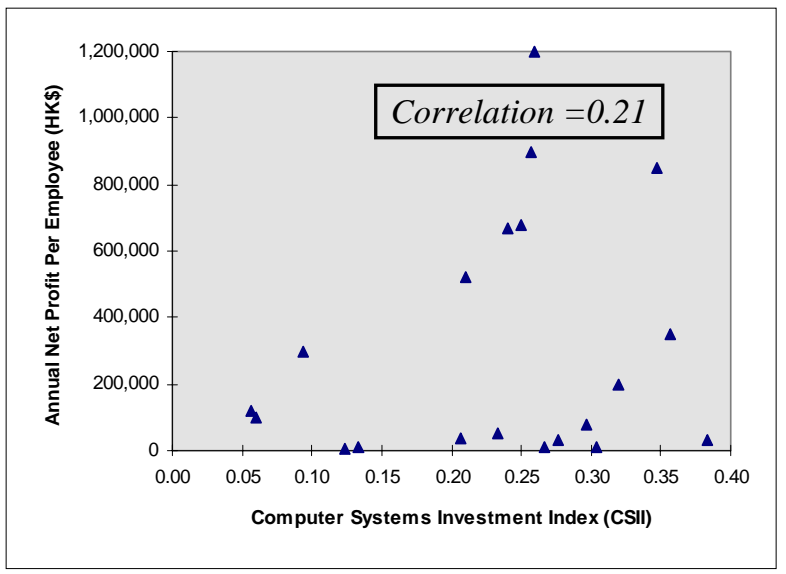

Figure 3: ITII vs. ANPEM for architectural firms

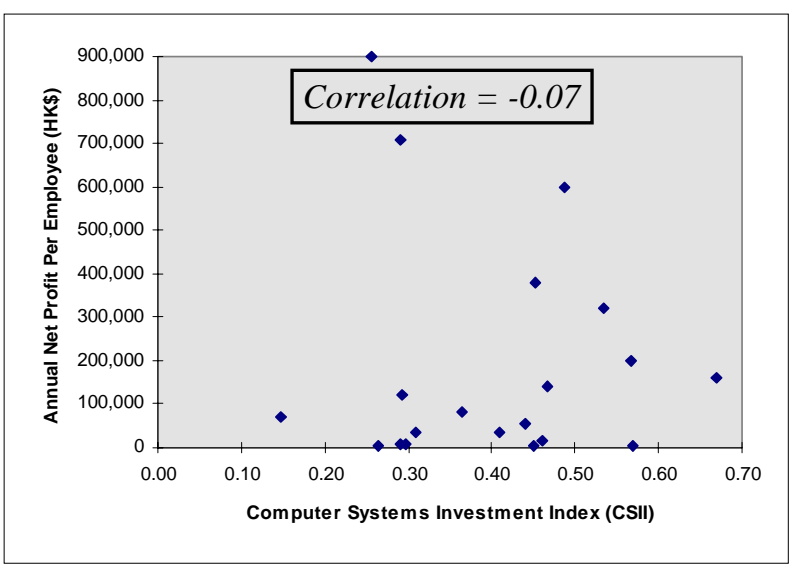

Figure 4. ITII vs. ANPEM for engineering firms

No significant correlation was found between the use of IT and annual net profit per employee in the engineering firms. This implies that the use of IT has little, and even a possible negative, impact on annual productivity. In other words, the use of IT and annual net profit per employee is an independent variable. In summary, according to our interpretation, results from statistical analyses seem to indicate that the use of IT in the QS firms indicate improvements in profitability, with IT having a positive but lower impact on architectural 
firm. However, statistical data collected from engineering firms do not support the rationale that the degree of IT applications is associated with organizational performance. Regression analyses were performed to further study the effect of the use of IT on the productivity. The following linear regression model was used:

ANPEM $=\mathrm{a}+\mathrm{b} * I T / I S I I$
Where:
ANPEM $=$ Annual Net Profit Per
Employee
$\quad I T I I=$ IT Investment Index

The confidence level selected for the regression analysis is $95 \%$. Table 1 presents the regression results for the selected sample. While the regression results indicate the linear model is not particularly suitable for capturing the relationship between ITII and $A N P E M$, the results clearly explain the large variance in productivity of QS firms.

Table 1: Regression results of ITII on ANPEM

\begin{tabular}{|c|c|c|c|}
\hline Engineering Firms & Beta & $\begin{array}{l}\text { Standard } \\
\text { error }\end{array}$ & Significance \\
\hline $\begin{array}{l}\text { a: Intercept } \\
\text { b: IT/ISII } \\
\mathrm{R}^{2}=0.004 \\
\mathrm{~F}=0.08\end{array}$ & $\begin{array}{l}245382 \\
-132068\end{array}$ & $\begin{array}{l}196529 \\
466954\end{array}$ & $\begin{array}{l}P<0.23 \\
P<0.79\end{array}$ \\
\hline $\begin{array}{l}\text { Architectural } \\
\text { Firms }\end{array}$ & Beta & $\begin{array}{l}\text { Standard } \\
\text { error }\end{array}$ & Significance \\
\hline $\begin{array}{l}\text { a: Intercept } \\
\text { b: IT/ISII } \\
\mathrm{R}^{2}=0.043 \\
\mathrm{~F}=0.82\end{array}$ & $\begin{array}{l}121022 \\
798050\end{array}$ & $\begin{array}{l}221124 \\
878281\end{array}$ & $\begin{array}{l}P<0.6 \\
P<0.4\end{array}$ \\
\hline QS Firms & Beta & $\begin{array}{l}\text { Standard } \\
\text { error }\end{array}$ & Significance \\
\hline $\begin{array}{l}\text { a: Intercept } \\
\text { b: IT/ISII } \\
\mathrm{R}^{2}=0.28 \\
\mathrm{~F}=7.05\end{array}$ & $\begin{array}{l}-183911 \\
474949\end{array}$ & $\begin{array}{l}108470 \\
178865\end{array}$ & $\begin{array}{l}P<0.11 \\
P<0.016\end{array}$ \\
\hline
\end{tabular}

The $R$-square for the linear model of QS firms is higher (0.28) than those from architectural and engineering firms, with the F-statistic being moderately significant $(\mathrm{P}<0.11)$. The $\mathrm{R}$-square for the regression model of architectural firms is lower (0.043) but higher than that generated from engineering firms. These again show support for the prediction of this study about a positive relationship between IT and productivity in QS firms; a positive but less significant, relationship in architectural firms; while there is no evidence to support such a positive relationship in engineering firms.

\section{LIMITATIONS OF RESEARCH}

One deficiency of this study is that the number of firms surveyed is relatively low. As an inescapable drawback of any empirical study, there is a possibility that the collected data might have led the authors to a biased view. Therefore, further studies are needed to collect a larger size of sample data to verify the correctness of the findings from this investigation. Also, it is necessary to conduct the same research project in other countries or regions to ensure the consistency and correctness of these research results. One difficulty encountered in performance measurement is that IT gradually accrues to a PCF as a whole, and is not always visible as improvements in the short-term performance of individual operations.

It is often difficult for a PCF to justify expenditure that cannot be related to specific projects or processes, which will not produce benefits until sometime in the future. To deal with this problem, it may be necessary to include dimensions representing the long-term profitability of the firm. As a result, the authors have identified three limitations in this study.

Firstly, it was observed in the survey that some of the respondents telephoned were not able to give accurate answers. For example, there was a very large variance in the answers for the fourth question (annual net profit per employee) among the respondents. Some of the figures were so small or so big that they do not seem to be realistic. However, in response to this, a written questionnaire may overcome this problem to some extent, but it may have some other side effects, e.g. the response rate and need for a representative sample. Nevertheless, this needs to be taken into account in our further studies. Second, although 20 firms represent a majority of the QS practices and architectural design professions, 20 engineering firms represent less than half of the size of the engineering services profession, as it is estimated that there are 80-100 construction related engineering firms in Hong Kong.

Therefore, additional data are needed from the engineering profession to further test the correctness of the research results. Third, the value of ITII was calculated as the average of the values of question 1,2 and 3, and the relative importance of the three values was not considered. In future studies, the authors will conduct sensitivity analyses to identify the relative importance of the three values as weightings, and ITII will be calculated as the weighted average of the three values.

\section{FUTURE RESEARCH}

Gupta and Capen (1996) suggest that the impact of IT/IS on organizational productivity is different between small and large companies. The research presented herein did not ask the respondents about the sizes of their companies, as a result there was 
no analysis of the difference of impact in company sizes. This will be addressed in a future quantitative study to be undertaken by the authors.

It was also noted that, in assessing the organizational impact of IT, many researchers tend to ask the respondents to assess the extent to which IT has improved the productivity of the companies. It is our observation that there is a big mismatch between what the managers/users of IT/IS think is the improvement, and what is the actual improvement in real productivity figures. In the light of this, the authors also plan to measure the difference between users' subjective assessment and the companies' objective productivity figures in our future studies.

As the construction industry is becoming more technology driven, investments in IT are likely to increase in the future. Unfortunately, most IT applications so far are brought into the industry without planning and evaluation. Much of the impact has been allowed to just happen, without accommodating changes in organizational structures and business processes (Love and Gunasekaran, 1997). The result has been that the 'full' potential of IT to improve organizations' efficiency, effectiveness and flexibility has seldom been reached (Love and McSparron, 1996). In future studies, attention must be paid to the measurement of productivity improvement brought by IT, and the interaction of IT with business methods, work patterns, employees and organizational culture.

\section{CONCLUSIONS}

The adoption of IT remains nebulous for a number of reasons, mainly due to the large number of interacting socio-technical variables involved in its implementation and use. As a result, the implications of adopting IT can be numerous, with some organizations achieving more gain than others from their exploitation of IT. This paper has sought to 'shed' light on the exploitation of new technology within a sample of companies. In doing so, identifying that companies that adopt IT are not guaranteed to increase their productivity.

The findings of this study seemed to indicate that the QS profession reaped productivity improvement from the use of IT. Architectural firms also appeared to have benefited from the use of IT. An important area of IT in architectural design is the use of computer-aided drafting and design tools. These tools have shortened the time required to provide architectural drawings and documentation. This study found little evidence to a positive relationship between the use of IT/IS and productivity increase in engineering firms.

\section{REFERENCES}

Abudayyeh, O. Y., and Rasdorf W. J. (1992). Design of construction industry information management systems. ASCE Journal of Construction Engineering and Management, 117(4), pp.698-715.

Ahmed, I.U., Russell, J.S., and Abou-Zeid, A. (1995). Information technology and integration in the construction industry. Construction Management and Economics, 13, pp.163-171.

Alter S. 1999. 'Information Systems: A Management perspective’. Addison-Wesley, Third Edition, USA.

Amorous, D. L., Springs, C. and Cheney, P. H. (1992). Quality end user-developed application: some essential ingredients. Database, Winter, pp. 1-11.

Best, R., De Valence, G., Langston, C., and Smith, P. (1996). Information technology and the evolution of the quantity surveying profession-future directions. Proceedings of the International Construction Information Technology Conference, $18^{\text {th }}-19^{\text {th }}$ April Sydney, Australia, pp.151-155.

Betts, M. (1995). Technology planning frameworks to guide national IT policy in construction. Automation in Construction, Elsevier Science, pp.251-266.

Björk, B-C. (1993). A case study of a national building industry strategy for computer integrated construction. In K. Mathur et al. (Eds.) Management of Information technology for Construction, World Scientific Publishing Co., Singapore, pp.89-99.

Bowen, W. (1986). The puny payoff form office computers, Fortune, May 26, pp. 20-24.

Bradburn, N., and Sudman, S. (1979). Improving Interview Method and Questionnaire Design. Holden Day, San Francisco.

Brandon, P. S., and Moore, R. G. (1983) Microcomputers in Building Appraisal, Granada Publishing, 1983.

Brynjolfsson E. (1994). Technology's true payoff. Information week, Issue 496, October, pp. 3436.

Choi, K.C., and Ibbs, C.W. (1990). CAD/CAE in construction: trends, problems, and needs. ASCE Journal of Management in Engineering, 6, pp.394-415.

Conrath, D. W. and Sharma (1992) R. S. Toward a diagnostic instrument for assessing the quality of expert systems, Database, Winter, pp. 3743 , 
Dawson, A.D. (1994). Computing in architectural practice: the reality. Proceedings of the ANZAScA Conference, $26^{\text {th }}-28^{\text {th }}$ September, Geelong, Victoria, Australia, pp.53-61.

Davis, F. D. (1989) Perceived usefulness, perceived ease of use, and user acceptance of information technology, MIS Quarterly, pp. 319-339.

Delone, W. H., and McLean, E. R. (1992). Information systems success: The quest for the dependent variable. Information Systems Research, 3(1), pp. 60-95.

English, L. P. (1993) DRM today, DRM tomorrow, Database Programming and Design, November.

Gupta, U.G., and Capen, M. (1996). An empirical investigation of the contribution of IS to manufacturing productivity, Information and Management, 31, pp. 227-233.

Hampson, K.D., and Tatum, C. B. (1994). Strategies for appropriate technology and competitive performance in infrastructure construction. Proceedings of the National Construction Management Conference, Sydney, Australia, pp.267-268.

Heath W and Swinden K. 1992. 'The chips are down for Europe'. Management Today, October, pp. 92-110.

Hochstrasser B. (1992). Justifying IT investments. Proceedings of the Advanced Information Systems Conference; The new technologies in today's business environment, UK, pp. 17-28.

Irani $\mathrm{Z}$ and Sharp J.M. (1997). Integrating continuous improvement and innovation into a corporate culture: A case study. The International Journal of Technological Innovation, Entrepreneurship and Technology Management (Technovation), 17(4), pp. 199206.

Irani Z, Sharp J.M and Kagioglou M. (1997). Improving business performance through developing a corporate culture. The International Bi-Monthly for Total Quality Management: The TQM Magazine, 9(3): pp.206-216.

Irani Z, Ezingeard J-N and Grieve R.J. (1998). Costing the true costs of IT/IS investments: A focus during management decision making. The Journal of Logistics and Information Management, 11(1), pp.38-43.

Irani Z, Ezingeard J-N and Grieve R.J. (1997). Integrating the costs of an IT/IS infrastructure into the investment decision making process. The International Journal of Technological Innovation, Entrepreneurship and Technology Management (Technovation), 17(11/12): pp.695-706
Keen, P. (1991). Shaping the Future: Business Design through Information Technology. Harvard Business School Press, Boston.

Li, H. (1996a). Toward quantifying the benefits of IT investment in construction. Building Research and Information. 24(6), pp.379-382.

$\mathrm{Li}, \mathrm{H}$. (1996b). The role of IT in construction process re-engineering, Building Research and Information, 24(2), pp.124-128.

Love, P.E.D., Li, H., and Mandal, P. (1999). Rework: a symptom of a dysfunctional supplychain. European Journal of Purchasing and Supply Management, 5(1), pp.1-11.

Love, P.E.D., and Gunasekaran, A. (1997). Process re-engineering: a review of enablers. International Journal of Production Economics. 50(2/3), pp.183-197.

Love, P.E.D. (1996). Enablers of Process Reengineering. International Construction Information Technology Conference, Sydney, Australia, $18^{\text {th }}-19^{\text {th }}$ April, pp.77-84.

Love, P.E.D., MacSporran, C., and Tucker, S.N. (1996). The application of information technology by Australian contractors: toward process re-engineering. Fourth International Conference on Lean Construction, $25^{\text {th }}-27^{\text {th }}$ August. University of Birmingham, UK.

Love, P.E.D., and MacSparron, C. (1996). The Use Information Technology by Australian Construction Contractors. The Chartered Building Professional. June, pp.14-18.

Sandivo, V.E., and Medieiros, D.J. (1990). Applying computer-integrated manufacturing concepts to construction. ASCE Journal of Construction Engineering and Management, 116, pp.365-379.

Scott Morton, M. S. (1991). The Corporation of the 1990's: Information Technology and Organizational Transformation. Oxford University Press, New York.

Strassman, P. (1990). The Business Value of Computers. The Information Economics Press, New Canaan, CI.

Taylor, J.C. (1987). Job Design and Quality of Working Life. In Technology and Transformation of White Collar Work, Hillsdale Publications, New Jersey pp.211235.

Tucker, S.N., Love, P.E.D, Tilley, P.A., Salomonsson, G.S., MacSporran, C. and Mohamed, S. (1996). Perspectives of Construction Contractors Communication and Performance Practices: Pilot Survey Report. May, CSIRO, DBCE DOC 96/29 (M).

Young, T. R. (1984) The lonely micro, Datamation, pp. 100-113, April. 
APPENDIX 1: SURVEY RESULTS FROM ENGINEERING FIRMS

\begin{tabular}{|c|c|c|c|c|}
\hline $\begin{array}{c}\text { Firm } \\
\text { No }\end{array}$ & $\begin{array}{c}\text { Question } \\
\mathbf{1}\end{array}$ & $\begin{array}{c}\text { Question } \\
\mathbf{2}\end{array}$ & $\begin{array}{c}\text { Question } \\
\mathbf{3}\end{array}$ & $\begin{array}{c}\text { Question } \\
\mathbf{4}(\mathbf{H K} \mathbf{)})\end{array}$ \\
\hline 1 & 0.34 & 0.41 & 0.13 & 120,000 \\
\hline 2 & 0.76 & 0.54 & 0.02 & 55,000 \\
\hline 3 & 0.82 & 0.43 & 0.35 & 320,000 \\
\hline 4 & 0.22 & 0.38 & 0.27 & 7,000 \\
\hline 5 & 0.56 & 0.42 & 0.37 & 3,000 \\
\hline 6 & 0.63 & 0.35 & 0.42 & 140,000 \\
\hline 7 & 0.36 & 0.42 & 0.11 & 7,000 \\
\hline 8 & 0.69 & 0.22 & 0.32 & 36,000 \\
\hline 9 & 0.50 & 0.21 & 0.08 & 3,700 \\
\hline 10 & 0.31 & 0.44 & 0.34 & 81,000 \\
\hline 11 & 0.91 & 0.32 & 0.23 & 600,000 \\
\hline 12 & 0.73 & 0.49 & 0.48 & 200,000 \\
\hline 13 & 0.42 & 0.28 & 0.17 & 710,000 \\
\hline 14 & 0.25 & 0.32 & 0.36 & 34,000 \\
\hline 15 & 0.35 & 0.31 & 0.11 & 900,000 \\
\hline 16 & 0.82 & 0.46 & 0.73 & 160,000 \\
\hline 17 & 0.19 & 0.18 & 0.07 & 70,000 \\
\hline 18 & 0.52 & 0.32 & 0.54 & 17,000 \\
\hline 19 & 0.85 & 0.49 & 0.37 & 5,200 \\
\hline 20 & 0.54 & 0.36 & 0.46 & 380,000 \\
\hline & & & & \\
\hline
\end{tabular}

APPENDIX 2: SURVEY RESULTS FROM ARCHITECTURAL FIRMS

\begin{tabular}{|l|l|l|l|l|}
\hline $\begin{array}{l}\text { Firm } \\
\text { No }\end{array}$ & $\begin{array}{l}\text { Question } \\
\mathbf{1}\end{array}$ & $\begin{array}{l}\text { Question } \\
\mathbf{2}\end{array}$ & $\begin{array}{l}\text { Question } \\
\mathbf{3}\end{array}$ & $\begin{array}{l}\text { Question } \\
\mathbf{4}(\mathbf{H K} \mathbf{)})\end{array}$ \\
\hline 1 & 0.10 & 0.07 & 0.01 & 100,000 \\
\hline 2 & 0.21 & 0.19 & 0.30 & 50,000 \\
\hline 3 & 0.32 & 0.33 & 0.10 & 680,000 \\
\hline 4 & 0.06 & 0.02 & 0.20 & 300,000 \\
\hline 5 & 0.32 & 0.20 & 0.10 & 35,000 \\
\hline 6 & 0.37 & 0.18 & 0.25 & 12,000 \\
\hline 7 & 0.36 & 0.21 & 0.15 & 670,000 \\
\hline 8 & 0.43 & 0.27 & 0.08 & 1200,000 \\
\hline 9 & 0.05 & 0.17 & 0.15 & 5,000 \\
\hline 10 & 0.41 & 0.35 & 0.20 & 200,000 \\
\hline 11 & 0.25 & 0.32 & 0.34 & 8,000 \\
\hline 12 & 0.17 & 0.20 & 0.03 & 10,000 \\
\hline 13 & 0.20 & 0.36 & 0.27 & 30,000 \\
\hline 14 & 0.32 & 0.42 & 0.30 & 850,000 \\
\hline 15 & 0.19 & 0.28 & 0.30 & 900,000 \\
\hline 16 & 0.07 & 0.09 & 0.01 & 120,000 \\
\hline 17 & 0.38 & 0.42 & 0.35 & 30,000 \\
\hline 18 & 0.37 & 0.50 & 0.20 & 350,000 \\
\hline 19 & 0.25 & 0.28 & 0.10 & 520,000 \\
\hline 20 & 0.33 & 0.36 & 0.20 & 80,000 \\
\hline & & & & \\
\hline
\end{tabular}

APPENDIX 3: SURVEY RESULTS FROM QUANTITY SURVEYING FIRMS

\begin{tabular}{|c|c|c|c|c|}
\hline $\begin{array}{c}\text { Firm } \\
\text { No }\end{array}$ & $\begin{array}{c}\text { Question } \\
\mathbf{1}\end{array}$ & $\begin{array}{c}\text { Question } \\
\mathbf{2}\end{array}$ & $\begin{array}{c}\text { Question } \\
\mathbf{3}\end{array}$ & $\begin{array}{c}\text { Question } \\
\mathbf{4}(\mathbf{H K} \mathbf{\text { ) }}\end{array}$ \\
\hline 1 & 1.03 & 0.57 & 0.20 & 120,000 \\
\hline 2 & 0.73 & 0.63 & 0.24 & 80,000 \\
\hline 3 & 0.80 & 0.64 & 0.43 & 38,000 \\
\hline 4 & 1.10 & 0.72 & 0.51 & 160,000 \\
\hline 5 & 0.97 & 0.43 & 0.32 & 48,000 \\
\hline 6 & 1.00 & 0.47 & 0.38 & 55,000 \\
\hline 7 & 1.00 & 0.84 & 0.10 & 270,000 \\
\hline 8 & 0.75 & 0.77 & 0.07 & 90,000 \\
\hline 9 & 0.95 & 0.43 & 0.31 & 67,000 \\
\hline 10 & 0.93 & 0.82 & 0.40 & 157,000 \\
\hline 11 & 0.69 & 0.41 & 0.05 & 47,000 \\
\hline 12 & 0.82 & 0.53 & 0.62 & 220,000 \\
\hline 13 & 0.94 & 0.71 & 0.11 & 60,000 \\
\hline 14 & 0.73 & 0.93 & 0.20 & 35,000 \\
\hline 15 & 0.80 & 0.56 & 0.32 & 52,000 \\
\hline 16 & 0.98 & 0.75 & 0.21 & 210,000 \\
\hline 17 & 0.92 & 0.78 & 0.09 & 31,000 \\
\hline 18 & 1.00 & 0.45 & 0.32 & 68,000 \\
\hline 19 & 1.03 & 0.57 & 0.30 & 150,000 \\
\hline 20 & 0.88 & 0.64 & 0.22 & 79,000 \\
\hline
\end{tabular}

